threshold dose, laser irradiation has an inhibitory effect on tumour growth as opposed to its simple thermal effect. Our experience suggests, however, that this potential "cure" cannot be achieved in clinical practice. Simple laser irradiation, as opposed to laser irradiation after previous photosensitisation of tumour tissue with haematoporphyrin dye, ${ }^{12}$ therefore holds little hope of cure except, perhaps, in rare instances of slowgrowing polypoid tumours within the bronchial lumen. Surgery, however, is the treatment of choice for such growths.

We thank Dr T Northfield, Dr P Salmon, Dr R Vicary, and Mr J Kirkham for inviting us to join them in use of laser facilities at our three hospitals. The study is supported by a grant from the Office of the Chief Scientist, Department of Health and Social Security.

Correspondence and requests for reprints should be sent to Dr F J C Millard at St James's Hospital, Balham, London SW12 8HW.

\section{References}

${ }^{1}$ Karnofsky DA, Burchenal JH. The clinical evaluation of chemotherapeutic agents in cancer. In: MacLeod C, ed. Evaluation of chemotherapeutic agents. New York: Columbia University Press, 1948.

${ }^{2}$ Medical Research Council. Questionnaire on respiration symptoms. London: Medical Research Council, 1966.

${ }^{3}$ Denison DM, Waller JF, Turton CWG, Sopwith T. Does the lung work ? Breathing in and breathing out. BrF Dis Chest 1982;76:237-53.

4 Butland RJA, Pang JA, Gross ER, Woodcock AA, Geddes DM. Two-, six-, and 12-minute walking tests in respiratory disease. $\mathrm{Br} M e d \mathcal{f} 1982$; 284:1607-8.
${ }^{5}$ Brown SG, Salmon PR, Kelly DF, et al. Argon laser photocoagulation in the dog's stomach. Gut $1979 ; 20: 680-7$.

6 Vourc'h G, Tanniers ML, Toty L, Personne C. Anaesthetic management of tracheal surgery using the neodynium-yttrium-aluminium-garnet laser. Br F Anaesth 1980;52:993-7.

' Toty L, Personne C, Colchen A, Vourc'h G. Bronchoscopic management of tracheal lesions using the neodynium-yttrium-aluminium-garnet laser. Thorax $1981 ; \mathbf{3 6}: 175-8$.

${ }^{8}$ Dumon JF, Reboud E, Garbe L, Aucomte F, Meric B. Treatment of tracheobronchial lesions by laser photoresection. Chest $1982 ; 81: 278-84$.

${ }^{9}$ Oko K, Ohtani T, Amemiya R, et al. Laser surgery in the trachea and bronchus via the fibreoptic bronchoscope [Abstract]. In: Atsumi K, Nimsakul N, eds. Proceedings of 4th congress of International Society for Laser Surgery, Tokyo, November 1981. Tokai University, Kanagawa: International Society for Laser Surgery, 1981:16-9.

10 Yamada R, Amemiya R, Ohtani $T$, et al. Indications and complications of Nd-YAG laser surgery via the fibreoptic bronchoscope in cases involving the trachea and major bronchi [Abstract]. In: Atsumi K, Nimsakul N, eds. Proceedings of 4th congress of International Society for Laser Surgery, Tokyo, November 1981. Tokai University, Kanagawa: International Society for Laser Surgery, 1981:21-4.

11 Tamada J, Ito $M$, Teramatsu $T$. Clinical study of bronchofibrescopic Nd-YAG laser surgery [Abstract]. In: Atsumi K, Nimsakul N, eds. Proceedings of 4th congress of International Society for Laser Surgery, Tokyo, November 1981. Tokai University, Kanagawa: International Society for Laser Surgery, $1981: 13-5$.

12. Hayata Y, Kato H, Konaka C, Ono J, Takizawa N, Kato W. Haematoporphyrin derivative and laser photoirradiation in the treatment of lung cancer. Chest $1982 ; 81: 269-77$.

${ }^{13}$ Gardner W, Hugh-Jones P, Carroll MA, Hewitt ER, Hewitt HB, Whimster W. Quantitative analysis of effect of neodynium-YAG laser on transplanted mouse carcinomas. Thorax $1982 ; 37: 594-7$.

(Accepted 12 November 1982)

\title{
Increased incidence of malignancy in dermatitis herpetiformis
}

\author{
J N LEONARD, W F G TUCKER, J S FRY, CARMEL A E COULTER, A W BOYLSTON, \\ R M H MCMINN, G P HAFFENDEN, A F SWAIN, LIONEL FRY
}

\begin{abstract}
A retrospective study of 109 patients with dermatitis herpetiformis showed that malignant tumours had developed in seven patients, the expected incidence being 2.93 , giving a relative risk of 2.38 . In three of the seven patients the malignancy was a lymphoma, giving a relative risk of 100 for this tumour (expected incidence 0.03). In six of the seven patients who developed malignancies small-intestinal biopsy specimens were macroscopically abnormal, giving a relative risk of $4 \cdot 22$ in this
\end{abstract}

St Mary's Hospital, London W2 1NY

J N LEONARD, $M B$, MRCP, honorary senior registrar, dermatology department

W F G TUCKER, MB, MRCP, registrar, dermatology department

CARMEL A E COULTER, MRCP, FRCR, consultant, radiotherapy department

G P HAFFENDEN, FIMLS, senior chief medical laboratory scientific officer, histopathology department

A F SWAIN, MB, MRCP, senior registrar, dermatology department

LIONEL FRY, MD, FRCP, consultant, dermatology department

St Mary's Hospital Medical School, London W2

J S FRY, PHD, lecturer, epidemiology department

A W BOYLSTON, MD, MRCPATH, senior lecturer, histopathology department

Anatomy Department, Institute of Basic Medical Sciences, Royal College of Surgeons of England, London WC2

R M H MCMINN, MD, PHD, emeritus professor group, which is similar to that reported in adult coeliac disease. Patients treated with a gluten-free diet appeared to have a reduced risk of developing malignancy compared with those taking a normal diet (relative risk with gluten-free diet 1.01 and with normal diet 3.09). A small subgroup of eight patients with linear IgA dermatitis herpetiformis were also studied: three developed malignant disease and in one the tumour was a lymphoma.

\section{Introduction}

An increased incidence of malignant disease, particularly lymphoma, has been reported in patients with adult coeliac disease. ${ }^{1-3}$ Most patients with dermatitis herpetiformis have an associated gluten-sensitive enteropathy. ${ }^{45}$ Although there have been isolated reports of small-intestinal lymphoma in individual patients with dermatitis herpetiformis, ${ }^{6-8}$ the incidence of malignancy in this condition has not been reported. We undertook a study to determine whether there is an increased incidence of malignant disease in dermatitis herpetiformis and, if so, any predisposing factors.

\section{Patients and methods}

One hundred and nine patients who had been followed up in the dermatitis herpetiformis clinic at St Mary's Hospital since 1969 were included in the study. Dermatitis herpetiformis was diagnosed on the basis of clinical presentation, response of the rash to sulphones, 
and the demonstration, by direct immunofluorescence, of IgA deposits in the dermal papillae of skin that was not affected. Although some patients had considerably longer histories of dermatitis herpetiformis and had been diagnosed as having the condition earlier at other hospitals, for the purpose of this study the point of entry was taken as being their first attendance at the clinic.

Patients were considered to have been at risk from the point of entry into the study until 31 December 1981, when the survey was undertaken. If patients had not been seen in the clinic for six months a letter and questionnaire were sent to their general practitioner inquiring about their health, current treatment, and development of malignant disease. If replies were not forthcoming a letter was sent to the patient. Four patients could not be traced, and they were considered to have been at risk from the point of entry until their last outpatient attendance. Patients who developed a malignancy were withdrawn from the study at the time the malignancy was diagnosed.

Small-intestinal biopsy of the duodenal-jejunal flexure was performed using a Crosby capsule in 96 patients $(88 \%$ ) at presentation. The biopsy specimens were graded in respect of both the macroscopic and the microscopic appearance. Intraepithelial lymphocyte counts were performed as described by Fry et al. ${ }^{4}$ If the count was greater than 250 lymphocytes/1000 epithelial cells the biopsy specimen was considered to be microscopically abnormal.

Patients were also graded in respect of their diet. This was done by calculating, for each patient, the number of years for which they had taken either a normal diet or a gluten-free diet. Patients were considered to have been taking a gluten-free diet only if the diet was strict according to assessment by a dietitian. These patients were considered to have been taking a normal diet from the point of entry into the study until the start of the gluten-free diet. All other patients were considered to have been taking a normal diet throughout the period at risk.

Statistical evaluation was carried out by relating the observed incidence of malignancy to that expected from the 1976 Cancer Registry figures. The Cancer Registry was considered to provide the most reliable control figures, with an estimated incidence of reporting of over $90 \%$ in most regions in the United Kingdom. ${ }^{9}$ The 1976 figures were chosen because they fall at the midpoint of the study and should thus accommodate any general trend in the incidence of cancers over the 12 years. The relative risk in the group of patients as a whole, and whether a demonstrable enteropathy and a normal diet predisposed to malignancy, were calculated. The $95 \%$ confidence limits were calculated by standard statistical methods, assuming a Poisson distribution for observed deaths. ${ }^{10}$

In addition to the 109 patients with papillary IgA dermatitis herpetiformis a small subgroup of eight patients with linear IgA dermatitis herpetiformis was studied. This condition may clinically resemble papillary IgA dermatitis herpetiformis but differs in the pattern of IgA deposition in the skin, the IgA being found in a homogeneous-linear band along the dermoepidermal junction. ${ }^{11}$ All eight patients underwent small-intestinal biopsy, and none was treated with a gluten-free diet.

\section{Results}

Seven $(6.4 \%)$ of the 109 patients with papillary IgA dermatitis herpetiformis developed malignant disease, giving a relative risk of 2.38 . Table I shows the type of malignancy in each case. The mean time from presentation to diagnosis of malignant disease was 41 months (range 2-127 months). Three patients later died.

TABLE I-Type and site of malignancy and biopsy findings

\begin{tabular}{cllc}
\hline & & \multicolumn{2}{c}{ Small-intestinal biopsy } \\
\cline { 3 - 4 } $\begin{array}{c}\text { Case } \\
\text { No }\end{array}$ & Type of malignancy & $\begin{array}{c}\text { Macroscopic } \\
\text { appearance }\end{array}$ & $\begin{array}{c}\text { Intraepithelial } \\
\text { lymphocyte } \\
\text { count* }\end{array}$ \\
\hline 1 & Lymphoma & Convoluted & 130 \\
2 & Lymphoma & Convoluted & ND \\
3 & Lymphoma & Convoluted & 635 \\
4 & Carcinoma of lung & Convoluted & 356 \\
5 & Carcinoma of lung & Convoluted & CD \\
6 & $\begin{array}{l}\text { Carcinoma of lung } \\
\text { Somatostatinoma of } \\
\text { small intestine }\end{array}$ & Leaves & 278 \\
& & &
\end{tabular}

ND = Not done as specimen damaged during processing * Upper limit of normal $=250$ lymphocytes $/ 1000$ epithelial cells
TABLE II-Relation between small-intestinal mucosal damage and malignancy

\begin{tabular}{|c|c|c|c|c|}
\hline $\begin{array}{c}\text { Intestinal } \\
\text { biopsy }\end{array}$ & $\begin{array}{c}\text { No of } \\
\text { patients }\end{array}$ & $\begin{array}{l}\text { Observed } \\
\text { incidence of } \\
\text { malignancy }\end{array}$ & $\begin{array}{l}\text { Expected } \\
\text { incidence of } \\
\text { malignancy }\end{array}$ & $\begin{array}{c}\text { Relative } \\
\text { risk of } \\
\text { malignancy } \\
(95 \% \\
\text { confidence } \\
\text { limits) }\end{array}$ \\
\hline Macroscopic abnormality & 60 & 6 & $1 \cdot 42$ & $\begin{array}{c}4 \cdot 22 \\
(2 \cdot 55-5 \cdot 90)\end{array}$ \\
\hline Microscopic abnormality & 31 & 1 & $1 \cdot 18$ & $\begin{array}{c}0.85 \\
(0-2.69)\end{array}$ \\
\hline $\begin{array}{l}\text { Normal } \\
\text { Not done }\end{array}$ & $\begin{array}{r}5 \\
13\end{array}$ & & $\begin{array}{l}0.03 \\
0.29\end{array}$ & \\
\hline Total & 109 & 7 & $2 \cdot 93$ & $\begin{array}{c}2 \cdot 38 \\
(1 \cdot 22-3 \cdot 56)\end{array}$ \\
\hline
\end{tabular}

TABLE III-Relation between diet and malignancy

\begin{tabular}{lcccc}
\hline Diet & $\begin{array}{c}\text { Patient } \\
\text { years }\end{array}$ & $\begin{array}{c}\text { Observed } \\
\text { incidence of } \\
\text { malignancy }\end{array}$ & $\begin{array}{c}\text { Expected } \\
\text { incidence of } \\
\text { malignancy }\end{array}$ & $\begin{array}{c}\text { Relative } \\
\text { risk of } \\
\text { malignancy } \\
\text { (95\% } \\
\text { confidence } \\
\text { limits) }\end{array}$ \\
\hline Normal & 429 & 6 & 1.94 & $\begin{array}{c}3.09 \\
(1.65-4.53) \\
1.01 \\
(0-3.02)\end{array}$ \\
Gluten free & 242 & 1 & 0.99 & \\
\hline
\end{tabular}

All three lymphomas would, until recently, have been classified as reticulum-cell sarcomas, giving a relative risk for this disease of 100 (expected incidence 0.03). However, one tumour was considered to be malignant histocytosis of the intestine ${ }^{12}$ (case 1), one an immunoblastic lymphoma (Kiel) (case 2), and one a centroblastic lymphoma (Kiel) (case 3). Postmortem examination of the patient with the immunoblastic lymphoma showed no evidence of involvement of the small intestine. The two other patients were still alive.

In six of the seven patients who developed a malignancy smallintestinal biopsy specimens were macroscopically abnormal, giving a relative risk for this feature of $4 \cdot 22$ (table II). Intraepithelial lymphocyte counts were obtained in five of the seven patients (table I). In the remaining two patients a count could not be obtained because of damage to the epithelium at the time the biopsy was processed. Nevertheless, both of these specimens showed heavy infiltration with lymphocytes. In two of the three patients who developed a lymphoma the biopsy was remarkable in that the intraepithelial lymphocyte count was low despite a macroscopic abnormality of the mucosa. None of the 60 other patients in this study with a macroscopically abnormal mucosa had an intraepithelial lymphocyte count below 150 .

Thirty-six $(57 \%$ ) out of the 63 patients who were taking a normal diet had a macroscopically abnormal small intestine compared with $24(73 \%)$ of the 33 patients taking a gluten-free diet; these proportions were not significantly different. Of the seven patients who developed a malignancy, only one was taking a gluten-free diet at the time the tumour presented. The relative risk in the patients taking a normal diet was 3.09 compared with 1.01 in those taking a gluten-free diet (table III).

Of the eight patients with linear IgA dermatitis herpetiformis, three developed malignancies-namely, carcinoma of the bladder (one), malignant melanoma of the eye (one), and mixed centrocytic and centroblastic lymphoma (Kiel) (one). In these three patients small-intestinal biopsy specimens were macroscopically normal, but the patient who developed carcinoma of the bladder had a raised intraepithelial lymphocyte count of 323. All eight patients were taking a normal diet (a gluten-free diet has not been shown to be of benefit in this condition $\left.{ }^{11}\right)$. The mean time from presentation at the clinic to the onset of malignant disease was 60 months (range 12-87 months). The patient with the lymphoma died. Postmortem examination showed no evidence of small-bowel tumour.

\section{Discussion}

This study has shown that patients with dermatitis herpetiformis have a significantly increased risk of malignancy of $2 \cdot 38$. Comparison of this figure with the reported relative risk of malignancy of $4 \cdot 16$ in patients with adult coeliac disease ${ }^{2}$ suggests that patients with dermatitis herpetiformis are less at risk of developing a malignancy. However, the figures of Holmes et al ${ }^{2}$ 
may have been biased since seven of their 21 patients presented with malignancy and adult coeliac disease was diagnosed only retrospectively. This would have misleadingly increased the observed incidence of malignant disease. As in adult coeliac disease, the increase in malignancy in dermatitis herpetiformis is largely due to the significant increase in the incidence of lymphoma; the incidence of non-lymphomatous tumours is probably not greater than that in a control group. In our series three patients out of 109 developed lymphomas compared with four out of 202 with adult coeliac disease followed up for a similar length of time. ${ }^{3}$

The relative risk of malignancy in the group of patients in whom the macroscopic appearance of the small-intestinal mucosa was abnormal was $4 \cdot 22$, which is similar to that reported in adult coeliac disease. ${ }^{2}$ None of the patients with normal results on small-intestinal biopsy developed a malignancy. It is well established that when a single biopsy specimen is obtained only about $60 \%$ of patients with dermatitis herpetiformis show a macroscopic change of the small-intestinal mucosa as is found in coeliac disease, ${ }^{5}$ although a further $30 \%$ will have a raised intraepithelial lymphocyte count indicative of gluten sensitivity. Even in those patients with a macroscopically normal small intestine, however, instillation of gluten into the small bowel will induce morphological change in the mucosa. ${ }^{13}$ The increased risk of malignancy in those patients with macroscopically abnormal small-intestinal mucosa does not necessarily imply that the damaged mucosa is the predisposing factor to malignant change. It might be argued that the factors that allow the smallintestinal mucosa to be damaged also confer a susceptibility to malignant disease. Small-intestinal damage in gluten sensitivity might well be an expression of altered immunocompetence, and this might predispose to malignancy.

This study also showed that patients taking a normal diet had a significantly increased risk of developing a malignant disease of 3.09, which was not the case in patients taking a gluten-free diet (relative risk 1.01). The $95 \%$ confidence limits for the two groups, however, overlapped. This implies that there is a trend towards a gluten-free diet being protective against the development of malignancy, though a longer period of follow-up is required for this to be statistically proved. The alternative explanation, that treatment with sulphones predisposes to malignancy, seems unlikely, as patients with adult coeliac disease do not take dapsone and yet have an increased incidence of malignancy. The suggestion that patients taking a gluten-free diet have a lower relative risk of developing malignancy than those taking a normal diet is contrary to the findings of Holmes et al in adult coeliac disease, ${ }^{2}$ who found no evidence that a gluten-free diet afforded protection against malignancy. In general the enteropathy in dermatitis herpetiformis is considerably less severe than that in adult coeliac disease. Adult coeliac disease is diagnosed only because of symptoms arising from the enteropathy, whereas in dermatitis herpetiformis patients rarely have symptoms of enteropathy. Possibly the increased severity of enteropathy in adult coeliac disease represents a greater underlying predisposition to malignancy that cannot be reversed by a gluten-free diet. Alternatively, as Holmes et al suggested, a gluten-free diet might have to be started early in the life of a patient with coeliac disease to prevent malignancy. Finally, a longer period of follow-up, as suggested by these workers, might possibly show benefit from a gluten-free diet in adult coeliac disease. If a gluten-free diet does protect against malignancy then there are important implications for the management of dermatitis herpetiformis. Although a gluten-free diet will clear the rash in dermatitis herpetiformis, ${ }^{51415}$ many dermatologists still choose to treat their patients with drugs rather than diet.

The finding of a low intraepithelial lymphocyte count in association with macroscopically abnormal small-intestinal mucosa in two of the three patients with dermatitis herpetiformis who developed a lymphoma is similar to that reported by Ferguson et al, ${ }^{16}$ who found low counts in patients with coeliac disease who developed lymphomas. This finding is important for two reasons. Firstly, it is possible that these patients are particularly at risk of developing lymphomas and should therefore be followed up carefully and treated with a gluten-free diet. Secondly, the immune mechanisms of these patients should be investigated to try to determine the nature of the different response to gluten compared with those patients who show heavy infiltration of the mucosa.

The preliminary results in the small group of patients with linear IgA dermatitis herpetiformis indicate an increased risk of malignancy. This group of patients, however, has a much lower incidence of of associated enteropathy compared with patients with papillary dermatitis herpetiformis, ${ }^{11}$ and, as yet, there is no evidence that the rash in these patients is gluten dependent. If further work shows conclusively that the risk of malignancy in linear IgA dermatitis herpetiformis is the same as that in papillary dermatitis herpetiformis, and that gluten is not responsible for the rash in the former condition, it is likely that another factor, common to adult coeliac disease and linear IgA and papillary dermatitis herpetiformis, causes the malignancy. This might be a genetic or immunological defect, or both, which predisposes both to the development of the diseases and to malignant change. In this instance the gluten-sensitive enteropathy would be not the cause of the malignancy in patients with dermatitis herpetiformis and adult coeliac disease but a pointer that these patients are particularly prone to develop malignant disease.

We thank all the dermatologists who have referred patients to the dermatitis herpetiformis clinic since 1969. We are also grateful to the clinicians who provided information and biopsy material on the patients who developed malignancies, and to the dietitians at St Mary's Hospital for their help in managing our patients.

JNL is in receipt of a grant from the Medical Research Council, and LF is in receipt of grants from the Wellcome Trust and the Coeliac Trust.

\section{References}

' Harris OD, Cooke WT, Thompson H, Waterhouse JAH. Malignancy in adult coeliac disease and idiopathic steatorrhoea. Am f Med 1967;42: 899-912.

"Holmes GKT, Stokes PL, Sorahan TM, Prior P, Waterhouse JAH, Cooke WT. Coeliac disease, gluten free diet and malignancy. Gut $1976 ; 17: 612-9$

Holmes GKT, Cooper BT, Cooke WT. Malignant lymphoma in coeliac disease. In: McNicholl B, McCarthy CF, Fottrell PF, eds. Perspectives in coeliac disease. Lancaster: MTP Press, 1978:301-8.

- Fry L, Seah PP, Harper PG, Hoffbrand AV, McMinn RMH. The small intestine in dermatitis herpetiformis. 7 Clin Pathol 1974;27:817-24.

${ }^{5} \mathrm{Katz}$ SI. Dermatitis herpetiformis-the skin and the gut. Ann Intern Med 1980;93:857-74

${ }^{6}$ Marks JM. In: Hekkens WTJM, Pena AS, eds. Coeliac disease. Proceedings of the second international coeliac symposium. Leiden: H E Stenfert Kroese BV, 1974:410.

Freeman HJ, Weinstein WM, Shnitka TK, Piercey JRA, Wensel RH. Primary abdominal lymphoma-presenting manifestation of celiac sprue or complicating dermatitis herpetiformis. Am F Med 1977;63: 585-95.

* Tonder M, Sorlie D, Kearney MS. Adult coeliac disease. A case with ulceration, dermatitis herpetiformis and reticulosarcoma. Scand $f$ Gastroenterol 1976;11:107.

${ }^{9}$ Office of Population and Census Surveys. Report of the advisory committee on cancer registration, 1980. London: HMSO, 1981.

10 Armitage P. Statistical methods in medical research. Oxford: Blackwell Scientific, 1971:426.

${ }^{11}$ Leonard JN, Haffenden GP, Ring N, et al. Adult linear IgA disease. Br $\mathcal{F}$ Dermatol 1982;107:301-16.

1 Isaacson P, Wright DH. Malignant histiocytosis of the small intestine; its relationship to malabsorption and ulcerative jejunitis. Hum Pathol 1978;9:661-7.

${ }^{13}$ Weinstein WM. Latent coeliac sprue [Abstract.] Gastroenterology 1973; 64:819.

14 Fry L, Seah PP, Riches DJ, Hoffbrand AV. Clearance of skin lesions in dermatitis herpetiformis after gluten withdrawal. Lancet $1973 ; \mathrm{i}: 288-91$.

15 Reunala $\mathrm{T}$, Blomquist $\mathrm{K}$, Tarpilla S, Holme H, Kangas K. Gluten free diet in dermatitis herpetiformis. Br f Dermatol 1977;97:473-80.

${ }^{16}$ Ferguson R, Asquith P, Cooke WT. The jejunal cellular infiltrate in coeliac disease complicated by lymphoma. Gut 1974;15:458.

(Accepted 12 October 1982) 